\title{
Selected spices and their combination modulate hypercholesterolemia-induced oxidative stress in experimental rats
}

\author{
Gloria A Otunola ${ }^{1,3+}$, Oyelola B Oloyede ${ }^{2 \dagger}$, Adenike T Oladiji ${ }^{2 \dagger}$ and Anthony J Afolayan ${ }^{1 *+}$
}

\begin{abstract}
Background: Effect of aqueous extracts of Allium sativum (garlic), Zingiber officinale (ginger), Capsicum fructensces (cayenne pepper) and their mixture on oxidative stress in rats fed high Cholesterol/high fat diet was investigated. Rats were randomly distributed into six groups $(n=6)$ and given different dietary/spice treatments. Group 1 standard rat chow (control), group 2, hypercholesterolemic diet plus water, and groups 3, 4, 5, 6, hypercholesterolemic diet with $0.5 \mathrm{ml} 200 \mathrm{mg} \cdot \mathrm{kg}-1$ aqueous extracts of garlic, ginger, cayenne pepper or their mixture respectively daily for 4 weeks.
\end{abstract}

Results: Pronounced oxidative stress in the hypercholesterolemic rats evidenced by significant $(p<0.05)$ increase in MDA levels, and suppression of the antioxidant enzymes system in rat's liver, kidney, heart and brain tissues was observed. Extracts of spices singly or combined administered at $200 \mathrm{mg} . \mathrm{kg}-1$ body weight significantly $(p<0.05)$ reduced MDA levels and restored activities of antioxidant enzymes.

Conclusions: It is concluded that consumption of garlic, ginger, pepper, or their mixture may help to modulate oxidative stress caused by hypercholesterolemia in rats.

Keywords: Lipid peroxidation, Oxidative stress, Spices, Hypercholesterolemia, ROS

\section{Backgroud}

Hypercholesterolemia is a lipoprotein metabolic disorder characterized by high serum levels of low density lipoprotein (LDL-C) and blood cholesterol. Alteration in cholesterol and triglycerides metabolism as a result of hypercholesterolemia has been shown to negatively affect oxidative stress biomarkers and promotes production of reactive oxygen species (ROS) by various mechanisms, that leads to increased lipid peroxidation [1].

Oxidative stress is derivate from an imbalance between the generation of ROS and the endogenous antioxidant systems so that the latter is overwhelmed [2]. It has been reported to lead to increased lipid peroxidation, which in turn is involved in the aetiology of several chronic diseases [3]. The significant role of ROS in the pathogenesis of certain human diseases such as cardiovascular disease,

\footnotetext{
* Correspondence: aafolayan@ufh.ac.za

${ }^{\dagger}$ Equal contributors

${ }^{1}$ Current address Medicinal Plant and Economic Development Research Centre, Department of Botany, University of Fort Hare, Alice 5700, South Africa

Full list of author information is available at the end of the article
}

cancer, arthritis and post-ischemic re-oxygenation injury is increasingly being recognized [4]. ROS are highly reactive molecules derived from normal essential metabolic processes in the human body. They could also come from external sources such as exposure to X-rays, ozone, cigarette smoking, alcohol and industrial chemicals [5].

According to several reports, controlling ROS is believed to be more effective in preventing cardiovascular diseases with more potential for success than restrictive fat and cholesterol diets [6,7-9]. The significant role of ROS in the induction of oxidative damage to biomolecules is increasingly being reported $[4,10]$. Oxidative damage of cell membranes, DNA, and proteins induced by ROS has been implicated in the aetiology of several degenerative diseases like aging, cancer and cardiovascular diseases [11].

There is a growing interest in the mechanism of antioxidants in relation to damage caused by aggressive oxygen species and thiyl radicals. The main work of antioxidants seems to be scavenging these ROS and converting them to inactive substances [12]. Antioxidants are therefore crucial 
to the body's multilevel defense against free radicals. Lines of defense include enzymes (glutathione reductase, glutathione peroxidase, catalase, superoxide dismutase), vitamins ( $\mathrm{C}, \mathrm{E}$ and carotenoids), polyphenolics and other bioactive compounds, [13-15].

Spices are reported to contain natural chemicals like vitamins, phytonutrients, mineral elements, alkaloids, flavonoids, terpenoids and sesquisterpenes, [16]. These chemicals confer on spices, excellent antioxidant properties that help to neutralize free radicals in the body and prevent lipid peroxidation and mutation of DNA and healthy cells into cancerous cells, [17].

Garlic (Allium sativum), ginger (Zingiber officinale) and cayenne pepper (Capsicum fructensces) are common culinary spices that have been reported to possess antioxidant properties. The prophylactic and therapeutic effects of dietary garlic, ginger and pepper in reducing the risks of cardiovascular diseases, atherosclerosis, bacterial infections, inflammation, as well as vasodilator, anti-diabetic, anti-ulcer and hypocholesterolemic agents amongst others have been reviewed [16,18-21]. These spices are either used singly or combined in most cuisines all over the world. It is believed that when multiple antioxidants are used in combination, they prevent vulnerability to other agents and synergistically pool their antioxidant properties.

This study was therefore undertaken to assess the individual and combined additive or synergistic effects of the three spices-garlic, ginger and pepper on oxidative injury caused by dietary hypercholesterolemia in order to establish if combining the three will be more effective therapeutically using rat models.

\section{Results and discussion}

In this study, control rats fed normal diet were used as the reference point for each variable measured. Lipid peroxidation in the cardiac, hepatic, renal and brain tissues are presented in Figure 1. There was pronounced oxidative stress in the hypercholesterolemic rats as evidenced by significant $(\mathrm{p}<0.05)$ increase in MDA levels in the liver, heart, kidney and brain tissues compared with the control group. MDA in all the tissues of hypercholesterolemic rats was significantly $(\mathrm{p}<0.05)$ elevated compared to control. However, rats administered with $200 \mathrm{mg} / \mathrm{kg}$ body weight extract of any of the spices or their mixture exhibited significant $(\mathrm{p}<0.05)$ decrease in MDA levels when compared with the hypercholesterolemic rats, with the mixture extract showing the best modulatory action.

Figures 2, 3 and 4 depicts the altered activities of antioxidant enzymes namely SOD, GPex and GRed in the cardiac, hepatic, renal and brain tissues of rats. Compared to the control, the hypercholesterolemic rats showed a significant $(\mathrm{p}<0.05)$ depression in SOD, GPex and GRed activities. Hypercholesterolemic rats treated with 200 mg.kg-1 body weight of the spice extracts exhibited a significant $(\mathrm{p}<0.05)$ elevation of enzymes activities in all the tissues.

Hypercholesterolemic rats treated with extract of the mixture gave the best response for SOD and GRed indicating an additive effect of the three spices, while for GPex it was those treated with pepper extract that gave the best result.

Lipid peroxidation is a process associated with the pathogenesis of many chronic diseases such as atherosclerosis, cancer and diabetes. In this study, elevated cardiac, hepatic, renal and brain lipid peroxidation status in untreated hypercholesterolemic rats indicate increased oxidative injury and is consistent with reports from similar studies that showed that hypercholesterolemia leads to increased lipid peroxidation [22-24]. This effect was ameliorated following administration of $200 \mathrm{mg} / \mathrm{kg}$ body weight extract of the garlic, ginger, pepper and their mixture as evidenced by the reduced level of MDA. Ability of the spice extracts singly and combined to inhibit lipid peroxidation in vivo could be attributed to the free radical scavenging activities of their components especially phenols, flavonoids, and antilipidemic agents [25]. Similar observations were made by $[26,27]$ on the effect of cinnamon/garlic extracts and phenolic compounds from rosemary respectively on hypercholesterolemia induced oxidative stress in rats. Garlic, ginger and pepper have been reported to possess antioxidants especially flavonoids and phenolics which could account for their antioxidant activity [28-30].

Antioxidant enzymes such as SOD, GPex, and GRed catalyse the conversion of reactive oxygen species to harmless species. In this study, the reduced activities of hepatic, renal, cardiac and brain antioxidant enzymes in rats fed a hypercholesterolemic diet could be as a result of increased demand for these enzymes in deactivating the high influx of ROS generated by the high cholesterol diet, insufficiency of the enzymes, or failure of the antioxidant defence system to overcome the influx of reactive oxygen species [31,32]. Administration of $200 \mathrm{mg} / \mathrm{kg}$ extracts of garlic, ginger, pepper or their mixture significantly improved the antioxidant enzymes activities by restoring them almost to normal levels in the rats treated. These findings agree with earlier reports by other investigators on modulation of hypercholesterolemia induced oxidative stress in rats using Bacopa monniera, ascorbic acid, rutin and mushrooms respectively $[1,31,32]$.

\section{Conclusions}

Findings of this study suggest that extracts of garlic, ginger and pepper singly or combined possess antioxidant activity. Administration of a $200 \mathrm{mg} / \mathrm{kg}$ body weight aqueous extract of any of the spices significantly reduced lipid peroxidation and modulated effect of hypercholesterolemia 


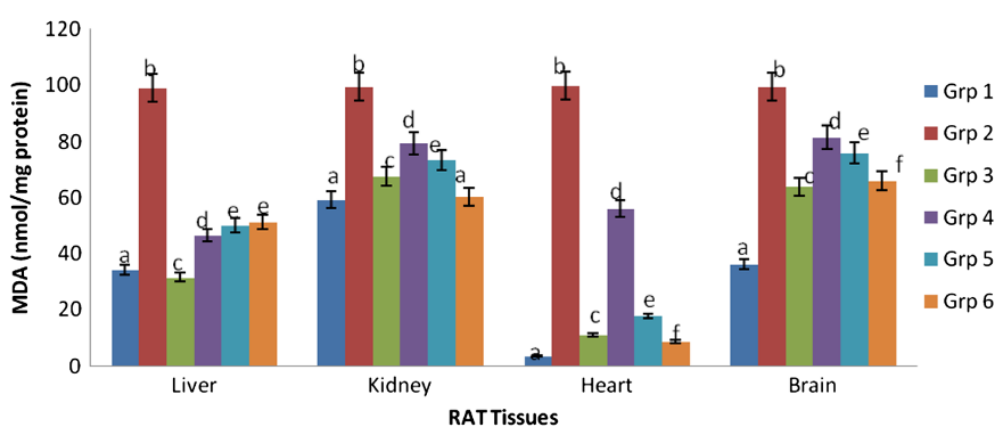

Figure 1 Effect of extracts of spices on malondialdehyde content in hypercholesterolemia-induced oxidative stress in rat tissues. a Values are means $\pm S D(n=6)$. ${ }^{b}$ Bars with different superscripts within the same tissues are significantly different at $p<0.05$. ${ }^{c}$ Malondialdehyde is expressed per milligram of protein. 'Grp 1-control, Grp 2- hypercholesterolemic diet, Grp 3- hypercholesterolemic diet + garlic, Grp 4- hypercholesterolemic diet + ginger, Grp 5- hypercholesterolemic diet + pepper, Grp 6- hypercholesterolemic diet + mixture.

induced oxidative stress, as well as improved the antioxidant defence system.

The results here therefore suggest that dietary consumption of these spices may provide benefits for patients with hypercholesterolemia-induced oxidative stress. The health implications of these findings may however be limited by the small group of rats used and the fact that these results may not be extrapolated to human populations. More detailed clinical studies involving human models may therefore be necessary.

\section{Methods}

\section{Preparation of spice extracts}

Garlic (Allium sativum), ginger (Zingiber officinale) and pepper (Capsicum fructensces) obtained from the local market in Ilorin, Nigeria, were individually sorted to remove grits and dirt, washed, thinly sliced, then oven-dried at $60^{\circ} \mathrm{C}$ for $72 \mathrm{~h}$. The dried spices were milled into fine powder, packed into airtight plastic bottles and stored in a cold room at $-20^{\circ} \mathrm{C}$ until needed. From the powdered samples, $50 \mathrm{~g}$ of each spice was extracted with $1 \mathrm{~L}$ of distilled water and boiled for $10 \mathrm{~min}$ at $100^{\circ} \mathrm{C}$. It was allowed to cool, filtered and freeze-dried (Vir Tis bench top K, Vir Tis, Gardiner, New York, USA) for 48 h. To prepare a mixture of the spices, equal amounts of each spice (50:50:50 g), were weighed and thoroughly mixed together by passing through a coffee grinder of a home blender set. From the mixture, $50 \mathrm{~g}$ was taken and extracted in like manner as described above. The freeze-dried samples were stored in airtight plastic bottles at $4^{\circ} \mathrm{C}$.

Dose equivalent to $200 \mathrm{mg}$ of each spice and their combination extract per kg body weight of rat was calculated and reconstituted in distilled water. These dose is consistent with reports from previous studies [33-36].

\section{Housing and management of animals}

Thirty six (36) male rats of Wistar strain weighing $168 \pm$ $10 \mathrm{~g}$ were randomly distributed into six groups, with six animals $(n=6)$ in each group after one week of acclimatization. They were exposed to a $12 \mathrm{~h} \mathrm{light/dark}$ cycle, constant temperature $\left(22^{\circ} \mathrm{C} \pm 2^{\circ} \mathrm{C}\right)$ and humidity $(70 \% \pm 4 \%)$ with water and feed made available ad libitum. The animals were handled according to the guidelines of the National Research Council Guide for the Care and

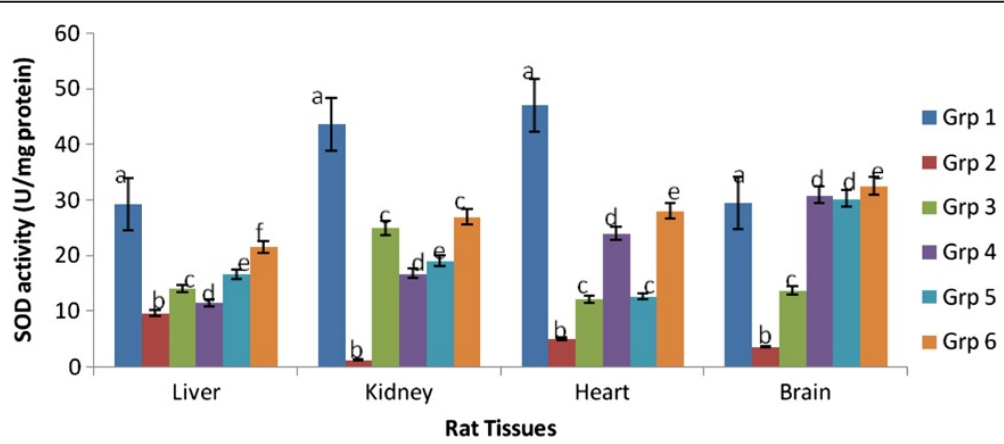

Figure 2 Effect of extracts of spices on superoxide dismutase activity in hypercholesterolemia-induced oxidative stress in rat tissues. a Values are means \pm SEM $(n=6, p<0.05)$. ${ }^{b}$ Bars with the same colour but different letters are significantly different. ${ }^{c}$ Grp1-control, Grp 2- hypercholesterolemic diet, Grp 3- hypercholesterolemic diet + garlic, Grp 4- hypercholesterolemic diet + ginger, Grp 5- hypercholesterolemic diet + pepper, Grp 6- hypercholesterolemic diet + mixture of spices. 


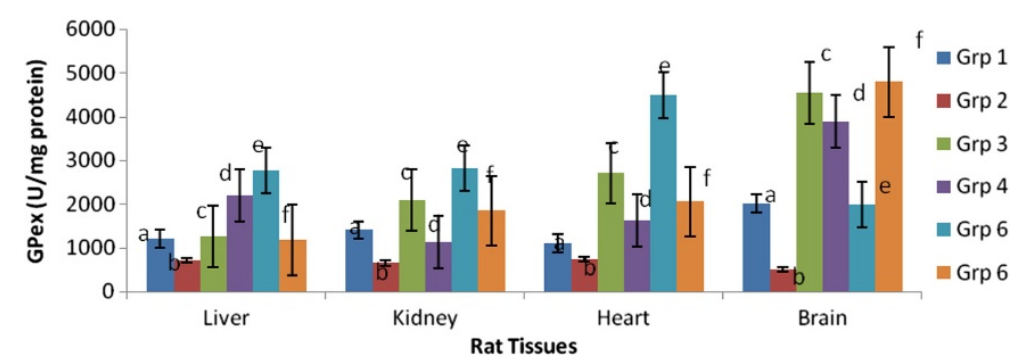

Figure 3 Effect of extracts of spices on glutathione peroxidase activity in hypercholesterolemia-induced oxidative stress in rat tissues. aValues are means \pm SEM $(n=6)(p<0.05)$. 'B Bars with the same colour but different letters are significantly different. 'Grp1- control, Grp 2hypercholesterolemic diet, Grp 3- hypercholesterolemic diet + garlic, Grp 4- hypercholesterolemic diet + ginger, Grp 5- hypercholesterolemic diet + pepper, Grp 6- hypercholesterolemic diet + mixture of spices.

Use of Laboratory Animals [37] and the study was approved by the Animal Ethics Committee, University of Fort Hare, Alice, South Africa.

\section{Experimental protocols}

Two diets, namely standard rat chow and hypercholesterolemic diet (1\% cholesterol and $25 \%$ soybean oil) that has been established to induce hypercholesterolemia $[38,39]$ were used. The diets were kept refrigerated and used within 1 week of preparation. Rats in group 1 (positive control), were fed the standard rat chow with water ad libitum. Group 2 (negative control) were fed the hypercholesterolemic diet and water, while groups 3, 4, 5, and 6 rats were fed the hypercholesterolemic diet and administered daily with aqueous extracts of garlic, ginger, pepper or their mixture at a dose equivalent to $200 \mathrm{mg} / \mathrm{kg}$ body weight of rats respectively.
At the end of 4 weeks, all the animals were fasted overnight and anaesthetized by intraperitoneal injection of pentobarbital sodium $(45 \mathrm{mg} / \mathrm{kg})$. Blood samples were collected by cardiac puncture into vacutainers (CE Sterile $R$ 456018P, greiner.bio.one, United Kingdom) for various biochemical analyses. The rats were finally euthanized and the heart, liver and kidney excised and rinsed in ice-cold saline to maintain physiologic status.

\section{Determination of lipid peroxidation and antioxidant}

enzymes activities in liver, kidney, heart and brain of rats Lipid peroxidation in the organs was determined by estimating levels of malondialdehyde (MDA) as described by [40]. This method was used to measure spectrophotometrically the color produced by the reaction of TBA with malondialdehyde at $532 \mathrm{~nm}$ using a Randox chemical assay kit. Tissue supernatants $(50 \mu \mathrm{l})$ were added to test

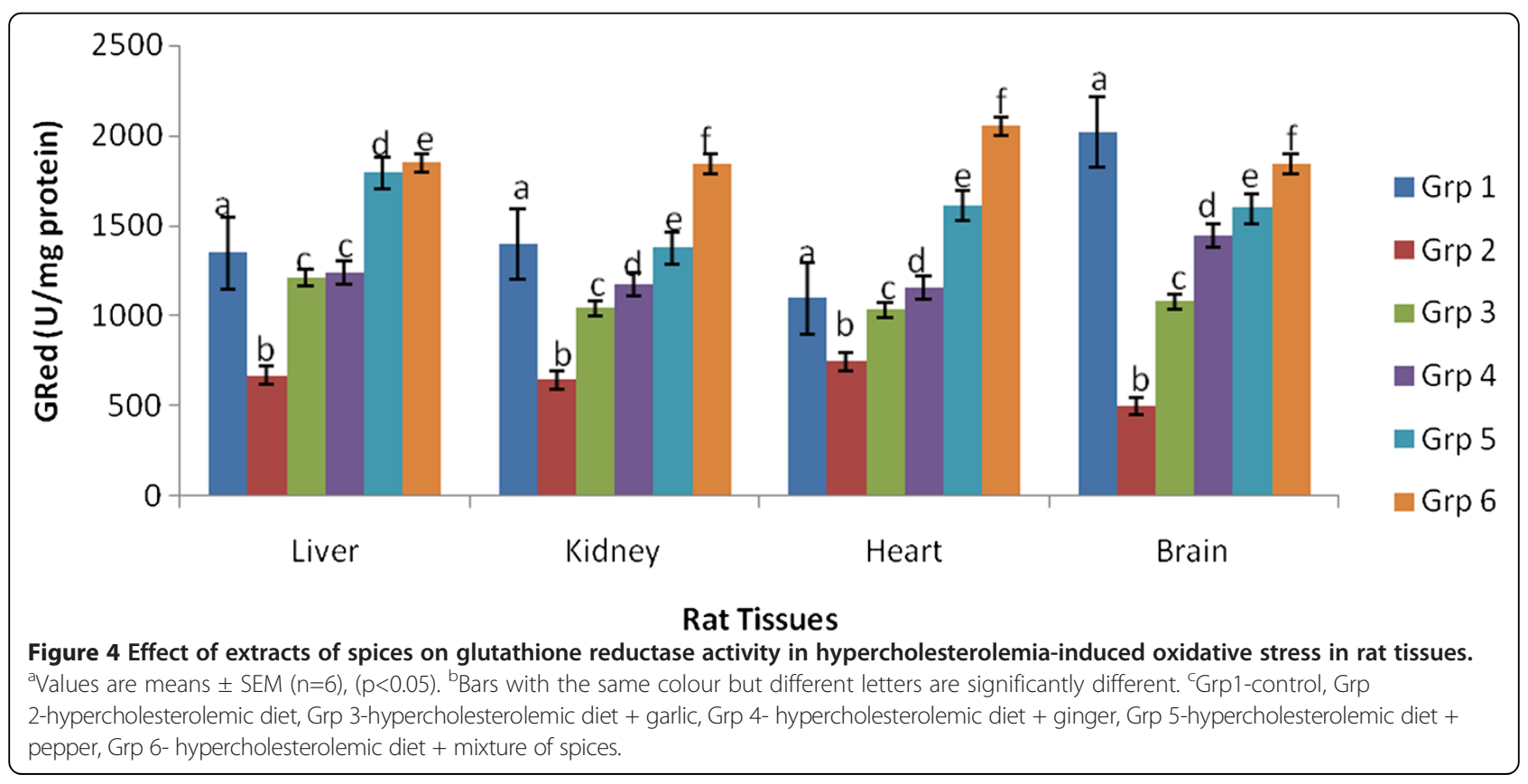


tubes containing $2 \mu \mathrm{l}$ of butylated hydroxytoluene (BHT) in methanol. Next, $50 \mu \mathrm{l}$ of acid reagent (1 M phosphoric acid) was added and finally $50 \mu \mathrm{l}$ of TBA solution was added. The tubes were mixed vigorously and incubated for $60 \mathrm{~min}$ at $60^{\circ} \mathrm{C}$. The mixture was centrifuged at $10,000 \times \mathrm{g}$ for $3 \mathrm{~min}$. The supernatant was put into microplate wells in aliquots of $75 \mu \mathrm{l}$, and absorbance was measured with a microplate reader at $532 \mathrm{~nm}$. TBARS levels were expressed as $\mathrm{nmol} / \mathrm{mg}$ protein in various organs (brain, liver, heart and kidney).

Activities of superoxide dismutase (SOD), glutathione peroxidase (GPex) and glutathione reductase (GRed) were assayed in the liver, heart, kidney and brain of experimental rats.

SOD accelerates the dismutation of the toxic superoxide radical $\left(\mathrm{O}_{2}\right)$ produced during oxidative energy processes to hydrogen peroxide and molecular oxygen. SOD was determined using Randox kits as described by [41]. The method uses xanthine and xanthine oxidase to generate superoxide radicals which reacts with 2-(4-iodophenyl)3-(4-nitrophenol)-5-phenyltetrazolium chloride (I.N.T) to form a red formazan dye which absorbs at $505 \mathrm{~nm}$. A $30 \mu \mathrm{l}$ of sample was pipetted into a cuvette with $1000 \mu \mathrm{l}$ of buffer (reagent 1) R1, and mixed well. To this mixture, $150 \mu \mathrm{l}$ of xanthine oxidase, (reagent 2) R2 was added and mixed, absorbance was read at $505 \mathrm{~nm}$.

Gpex activity was determined using Randox assay kit as described by the manufacturer based on the method of [42]. Glutathione peroxidase catalyses oxidation of glutathione by cumene hydroperoxide. In the presence of glutathione reductase and $\mathrm{NADPH}$, the oxidized glutathione (GSSG) is immediately converted to the reduced form with a concomitant oxidation of $\mathrm{NADPH}$ to $\mathrm{NADP}^{+}$. An aliquot $(10 \mu \mathrm{l})$ of the sample was added to $500 \mu \mathrm{l}$ of reagent $1\left(\mathrm{R}_{1}\right)$ and mixed. To this mixture was added $20 \mu \mathrm{l}$ of cumene $\left(\mathrm{R}_{2}\right.$ reagent 2). A blank was set up using $10 \mu \mathrm{l}$ of distilled water and absorbance was read at $340 \mathrm{~nm}$.

GRed activity was determined as described by [43] using Randox kits. Glutathione reductase catalyses the reduction of glutathione (GSSG) in the presence of $\mathrm{NADPH}$, which is oxidized to $\mathrm{NADP}^{+}$. The decrease in absorbance of the sample is measured at $340 \mathrm{~nm} .10 \mu \mathrm{l}$ of tissue sample was mixed with $250 \mu \mathrm{l}$ of substrate $R_{1}$ (reagent 1) after which $50 \mu \mathrm{l}$ of $R_{2}$ (reagent 2) was added, mixed and the timer started. Initial absorbance was read at1 min, read again after 2, 3, 4, and $5 \mathrm{~min}$.

\section{Statistical analysis}

Data were expressed as means \pm SEM from 6 determinations. Both descriptive and inferential statistical methods were used for data analysis. When the data were subjected to prior investigations before analysis, parametric assumptions including homoscedasticity, normality and independence of observations were satisfied. Hence, a parametric test (analysis of variance, ANOVA) was used to test for statistical significance among the treatment means. Differences among treatment means were considered significant at $\mathrm{P}<0.05$. Means that were significantly different from each other were segregated using Duncan's Multiple Range Test. All analyses were done using MINITAB (Student Version 12 for Windows) Software.

\section{Competing interests}

The authors report no conflicts of interests.

\section{Authors' contributions}

The study design was by GAO, OBO, ATO and AFO, GAO and AFO performed the experiments, $\mathrm{GAO}, \mathrm{OBO}, \mathrm{ATO}$ and $\mathrm{AFO}$ were involved in the writing of the manuscript. All authors read and approved the final manuscript.

\section{Acknowledgements}

This study was supported by Govan Mbeki Research Development Council, University of Fort Hare, South Africa.

\section{Author details}

${ }^{1}$ Current address Medicinal Plant and Economic Development Research Centre, Department of Botany, University of Fort Hare, Alice 5700, South Africa. ${ }^{2}$ Department of Biochemistry, University of Ilorin, Ilorin, Nigeria. ${ }^{3}$ Department of Home Economics and Food Science, University of Ilorin, Ilorin, Nigeria.

Received: 24 September 2013 Accepted: 9 December 2013

Published: 26 March 2014

\section{References}

1. Abuohashish HM, Aleisa AM, Ahmed MM, Alkhamees OA, Al-Rejaie SS, Alroujayee AS: Ameliorative effects of rutin and ascorbic acid combination on hypercholesterolemia-induced hepatotoxicity in female rats. Afr J Pharm Pharmacol 2013, 7(6):280-288.

2. Ahmad A, Singhal U, Hossain MM, Islam N, Rizvil I: The role of endogenous antioxidant enzymes and malondialdehyde in essential hypertension. J Clin Diaggnostic Res 2013, 7(6):987-990.

3. Kasdallah-Grissa A, Nakbi A, Koubaa N, El Fazaa S, Gharbi N, Kamoun A, Hammani M: Dietary virgin olive oil protects against lipid peroxidation and improves antioxidant status in the liver of rats chronically exposed to ethanol. Nutr Res 2008, 28:477-419.

4. Halliwell B, Gutteridge JMC: ROS in biology and medicine. Oxford, UK: Claredon Press; 1989:245-257.

5. Bagchi K, Puri S: ROS and antioxidants in Health and disease. East Mediterr Health J 1998, 4:350-360.

6. Maxwell SRJ, Lip GYH: Free radicals in cardiovascular diseases. Br J Clin Pharmacol 1997, 44(4):307-317.

7. Mimic-Oka J, Simic DV, Simic TP: Free radicals in cardiovascular diseases. Med Biol 1999, 6(1):11-22.

8. Kita T, Kune N, Minanim, Hayashida K, Murayana T, Sano H: Role of oxidized LDL in atherosclerosis. Ann N Y Acad Sci 2001, 947:199-205.

9. Reddy KS, Katan MB: Diet, nutrition and the prevention of hypertension and cardiovascular diseases. Public Health Nutr 2004, 7(1A):167-186.

10. Hazra B, Biswas S, Mandal N: Antioxidant and free radical scavenging activity of Spondias pinnata. BMC Compl Alter Med 2008, 8:63.

11. Fang D, Wei-Feng C, Bo Z, Li Y, Zhong-Li L: Antioxidative effects of curcumin and its analogues against the free-radical-induced peroxidation of linoleic acid in micelles. Phytother Res 2009, 23:1220-1228.

12. Stocker R, Frei B: Endogenous antioxidant defences in human blood plasma. In Oxidative stress, oxidants and antioxidants. Edited by Sies $\mathrm{H}$. London, UK: Academic Press; 1991:213-243.

13. Reddy ACP, Lokesh BR: Studies on spice principles as antioxidants in the inhibition of lipid peroxidation of rat liver microsomes. Mol Cell Biochem 1992, 111:117-124 
14. Reddy ACP, Lokesh BR: Alterations in lipid peroxidation in rat liver by $n-3$ fatty acids: modulation of anti-oxidant enzymes by curcumin, eugenol and vitamin E. J Nutr Biochem 1994, 5:181-188.

15. Adak SK, Sarkar AK, Bhattacharya P, Marmthu P, Chaudhuri RN, Barnerjee KK: Risk assessment of cardiovascular diseases among bank employees- a biochemical approach. Occup Med 1999, 49:313-318.

16. Srinivasan K: Spices as influencers of body metabolism: An overview of three decades of research. Food Res Int 2005, 38:77-86.

17. Shobana S, Naidu KA: Antioxidant activity of selected Indian spices. J Prostaglandins Leukotrien Essen Fatty acids 2000, 62:107-110.

18. Carmichael JK: Treatment of herpes and post herpetic neuralgia. Am Fam Phys 1991, 44:203-210.

19. Hoareau L, Dasilva EJ: Medicvinal plants: a re-emerging health aid. EJ Biotech 1999, 2(2):56-70.

20. Owen $\mathrm{PL}$, John T: Antioxidants in Medicines and spices as cardio protective agents in Tibetan Highlanders. Pharm Biol 2002, 40:346-357.

21. Shukla $Y$, Singh M: Cancer preventive properties of ginger: a brief review. Food Chem Toxicol 2007, 45:683-690.

22. Yang B, Kalimo KO, Kallio SE, Mattila LM, Katajisto JK, Kallio HP, Peltola OJ: Effects of dietary supplementation with seabuckthorn (Hippophae rhamnoides) seed and pulp oils on atopic dermatitis. J Nutr Biochem 1999, 10:622-630.

23. Dutta K, Bishayi B: Escherichia coli lipopolysaccharide administration alters antioxidant profile during hypercholesterolemia. Ind J Clin Biochem 2009, 24:179-183.

24. MA J, Qiao Z, Xiang X: Aqueous extract of Astragalus mongholicus ameliorates high cholesterol diet induced oxidative injury in experimental rat models. J Med Plant Res 2011, 5:855-858.

25. Oloyede OB, Otunola GA, Oladiji AT, Afolayan AJ: Comparative analysis of the chemical composition of three spices- Allium sativum L., Zingiber officinale Rosc and Capsicum frutescens L. commonly consumed in Nigeria. Afr J Biotech (2010b, 9:6927-6931.

26. Noori S, Azmat M, Mahboob T: Study on antioxidant effects of cinnamon and garlic extract in liver, kidney and heart tissue of rat. Biosci Res 2012, 9:17-22.

27. Osilva AM, Afonso MS, Carvalho EBT, Barros SBM, Rivelli DP, Rogero MM, Torres RP, Lottenberg AM, Mancini-Fillio J: Phenolic compounds from Rosemary (Rosmarinus officinalis L.) attenuate oxidative stress and reduce blood cholesterol concentrations in diet-induced hypercholesterolemic rats. Nutr Metab 2013, 10:19.

28. Orekhov AN, Grunwald J: Effects of garlic on atherosclerosis. Nutrition 1997, 13:656-663.

29. Nicoll R, Henein MY: Ginger (Zingiber officinale Roscoe): a hot remedy for cardiovascular disease? Int J Cardiol 2009, 131:408-409.

30. Wu CT, Chang NW, Wang SY, Lin CF, PEl RJ: Alpinia pricei Hayata rhizome extracts have suppressive and preventive potencies against hypercholesterolemia. Food Chem Toxicol 2010, 48:2350-2356.

31. Khan MDA, Rahman MM, Tania M, Uddin MDN, Ahmed S: Pleurotus sajor-caju and Pleurotus florida mushrooms improve some extant of the antioxidant systems in the liver of hypercholesterolemic rats. The Open Nutraceut J 2011, 4:20-24.

32. Kamesh $V$, Sumathi T: Effect of Bacopa monniera $L$ in attenuating hepatic oxidative stress in hypercholesterolemia induced rats. Asian J Pharm Clin Res 2012, 5:90-95.

33. Shanmugam KR, Ramakrishna CH, Mallikarjuna K, Reddy KS: Protective effect of ginger against alcohol-induced renal damage and antioxidant enzymes in male albino rats. Ind J Exper Biol 2010, 48:143-149.

34. Nwanjo $\mathrm{H}, \mathrm{OzE} \mathrm{G}$ : Antiarrythmic and antihyperlipidaemic potentials of aqueous garlic extract in hypercholesterolaemic rats. Int J Nutr Wellness 2006, 3:2.

35. Ahmadi R, Pishghdaus S, Mollamine F, Manfared MRZ: Comparing the effects of ginger and glinbenclamide on dihydroxybenzene metabolites produced in Stz-induced diabetic rats. Int J Endocrin Metab 2013, 11(4):e10266.

36. Abduljawad SH, Hassaneim MA, Heaader EA: Influence of aqueous extract of red chillis pepper as curative for gastric ulcer in albino rats. $J$ Nat Sci Res 2013, 3(4):78-87.

37. National Research Council: Guide for the Care and Use of Laboratory Animals, Committee on Care and Use of Laboratory Animals of the Institute of Laboratory Animal Resources DHHS Publication No. (NIH). 1985:85-93.

38. Paula H, Matos SL, Pedrosa ML, Oliveira EL, Santos RC, Chianca JNRDA, Silva ME: Dietary Models for inducing Hypercholesterolemia in rats. Braz Arch Biol Tech 2005, 48:203-209.

39. Otunola GA, Oloyede OB, Oladiji AT, Afolayan AJ: Hypolipidemic effect of aqueous extracts of selected spices and their mixture on diet-induced hypercholesterolemia in Wistar rats. Can J Pure App/ Sci 2012, 6:2063-2071.
40. Ohkawa $\mathrm{H}$, Ohisi $\mathrm{N}$, Yagi $\mathrm{K}$ : Assay for lipid peroxides in animal tissues by thiobarbituric acid reaction. Annu Rev Plant Physiol Plant Mol Biol 1979, 95:351-358.

41. Wooliams JA, Wiener G, Anderson PH, Mcmurray $\mathrm{CH}$ : Variation in the activities of glutathione peroxidase and superoxide dismutase and in the concentration of copper in the blood of various breed crosses of sheep. Res Vet Sci 1983, 34:69-77.

42. Paglia DE, Valentine WJN: Studies on the quantitative and qualitative characterization of erythrocyte glutathione peroxidase. Lab Clin Med 1967, 70:158-169.

43. Spooner RJ, Goldberg DM: Assay of glutathione reductase. In Methods of enzymatic analysis. 3rd edition. Edited by Bergmeyen HV. Deerfield Beach (Fla): Verlag Chemie; 1983:258-265.

doi:10.1186/0717-6287-47-5

Cite this article as: Otunola et al: Selected spices and their combination modulate hypercholesterolemia-induced oxidative stress in experimental rats. Biological Research 2014 47:5.

\section{Submit your next manuscript to BioMed Central and take full advantage of:}

- Convenient online submission

- Thorough peer review

- No space constraints or color figure charges

- Immediate publication on acceptance

- Inclusion in PubMed, CAS, Scopus and Google Scholar

- Research which is freely available for redistribution

Submit your manuscript at www.biomedcentral.com/submit
C Biomed Central 